Article

\title{
Impact of Game-Based Learning on Understanding Lean Construction Principles
}

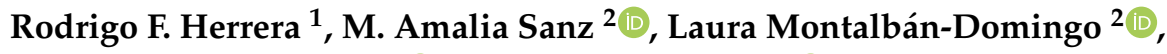 \\ Tatiana García-Segura ${ }^{2, *(D)}$ and Eugenio Pellicer ${ }^{3}$ (D) \\ 1 School of Civil Engineering, Pontificia Universidad Católica de Valparaíso, Pontificia Universidad Católica de \\ Chile \& Universitat Politècnica de València, Av. Brasil 2147, 2340000 Valparaíso, Chile; rodrigo.herrera@pucv.cl \\ 2 Construction Project Management Research Group, Universitat Politècnica de València, Camino de Vera s/n, \\ 46022 Valencia, Spain; asanz@cst.upv.es (M.A.S.); laumondo@upv.es (L.M.-D.) \\ 3 School of Civil Engineering, Universitat Politècnica de València, Camino de Vera s/n, 46022 Valencia, Spain; \\ pellicer@upv.es \\ * Correspondence: tagarse@upv.es; Tel.: +34-963-877-565
}

Received: 21 August 2019; Accepted: 23 September 2019; Published: 26 September 2019

check for updates

\begin{abstract}
Lean philosophy introduces a new approach for maximizing value while minimizing waste, facilitating sustainable practices at the same time. Companies have become aware of these improvements and are demanding students well formed in Lean concepts. However, to meet this demand, universities must adapt their curricula to include courses that use alternative teaching methods to connect to real contexts. This paper seeks to analyze the benefits of lecture- and game-based learning for developing students' understanding of Lean Construction Principles. A case study is carried out in the "Lean Construction" course of the Master of Planning and Management in Civil Engineering of the Universitat Politècnica de València. A combination of a traditional lecture and three simple games is applied. Descriptive statistics, the Mann-Whitney U-test, and the Wilcoxon test are performed to analyze the impact of each activity on the understanding of each Lean Construction Principle. Results highlight the importance of combining the lecture class with multiple games to effectively impart knowledge about Lean principles and their application in the construction industry. In addition, they emphasize the importance of selecting the game according to the Lean principle to be taught.
\end{abstract}

Keywords: game-based learning; lean construction; principles; construction industry; civil engineering; higher education

\section{Introduction}

The philosophy of Lean management has its origins in the Toyota Production System [1]. This philosophy presents new strategies of maximizing value while minimizing waste [2]. Lean philosophy, culture, and technology are the three key aspects for a global understanding of Lean [3]. Koskela [4] adapted this approach to the construction industry, introducing what is known as Lean Construction [5,6]. Koskela [4] proposed eleven important principles for flow process design and improvement: (1) reduce the share of non-value-adding activities; (2) increase output value through systematic consideration of customer requirements; (3) reduce variability; (4) reduce the cycle time; (5) simplify by minimizing the number of steps, parts, and linkages; (6) increase output flexibility; (7) focus control on the complete process; (8) increase process transparency; (9) build continuous improvement into the process; (10) balance flow improvement with conversion improvement; and (11) benchmark.

Some of these Lean Construction Principles (LCPs) are directly related to sustainability; for example, the flow view entails eliminating material waste that directly affects sustainability [7]. Researchers 
state that the synergy between Lean and sustainability is proven, since both approaches aim to reduce waste and prioritize cleaner production [8]. In addition, Martínez-León and Calvo-Amodio [9] noted that Lean tends to facilitate the adoption of environmental practices primarily by involving people and enhancing their problem-solving skill sets. This also represents an advantage for companies that adopt continuous improvement, as they tend to be more likely to implement environmental practices [10].

For all of the above reasons, the industry believes that graduates in the Architecture, Engineering, and Construction (AEC) field must be well-formed in Lean concepts and methods [11,12]. The application of Lean principles in the construction field can improve the efficiency of construction planning [13]. In view of the interests of academics and industry, universities are offering courses on Lean at both undergraduate and graduate levels [14]. Lean provides key skills for professionals in construction management [15]. However, traditional teaching methods do not effectively reach and convince the audience [16]. Some authors [17,18] have also indicated that traditional lectures present difficulties for learners in applying the information in an authentic context, particularly when being immersed in complex scenarios. Pellicer and Ponz-Tienda [19] and Nofera et al. [20] demonstrated the added value of using multiple teaching methods for students. Specifically, Kuriger et al. [21] stated that simulation games are effective tools for teaching Lean concepts, as participants can see and experience what they have learned in regular sessions through lectures and other teaching techniques.

Game-based learning (GBL) is a widely recognized teaching method in higher education due to its pedagogical benefits [22-24]. Using games as a teaching tool makes the learning process more enjoyable, which in turn makes the learners more receptive to the information the game's creator or the instructor intends to convey [25]. A game-based learning approach might be effective in facilitating students' skills development (e.g., collaboration, creativity, communication, or critical thinking, among others) [26]. GBL is a method with defined learning outcomes [27]. Usually, it is assumed that the game is a digital one. However, GBL can be any kind of game. A corollary to this definition is that the design process of GBL involves balancing the need to cover the subject with the desire to prioritize the game play [28]. Badurdeen et al. [29] presented a literature review of simulations used to teach Lean manufacturing for academic instruction and also for industry participants. Regarding Lean Construction, most of the games focus on project planning, such as Last Planner System Games [2,19,30,31]. GBL presents multiple advantages, but it is also important to consider its limitations. Deif [32] pointed out that GBL has the capability to motivate students and provides instructors with a tool for teaching Lean Construction in a practical manner, but it is important to take into account that Lean games must be adapted to the limited industrial experience of students [32]. González et al. [2] highlighted that one limitation of GBL is that games can sometimes be too complex to play and too complicated for implementation in university classes. Besides, as Hirota and Formoso [33] noted, it is not easy for students to understand and comprehensively incorporate the LCPs. To this end, Brioso [34] presented some activities including two simulation games to address the understanding of the LCPs. However, this author did not assess the effects of the activities on the learning of these principles, in contrast to González et al. [2], who evaluated the results but only focused on some of LCPs.

In this context, this paper proposes a combination of a traditional lecture and three simple games to learn Lean Construction Principles, analyzing the impact of each activity on the understanding of each LCP. These activities are implemented in a Master in Planning and Management in Civil Engineering program. Following the recommendations of González et al. [2], the learning experience of each student is evaluated through questionnaires at several stages: before starting each game and after the last game. Students also responded to a questionnaire that evaluated their understanding of each LCP after the lecture class.

The paper is organized as follows. Section 2 introduces the Lean Construction Principles. Section 3 presents the research process, describing its contextualization, the design of the learning activities, the questionnaires and the statistics used to analyze the results. Section 4 shows the results of each learning activity, as well as the discussion regarding the impact of each activity on the understanding 
of Lean Construction Principles. Finally, Section 5 presents the conclusions, providing the main contributions, limitations and future research.

\section{Lean Construction Principles (LCPs)}

Lean Construction serves two main goals during the construction process [35]: (1) to minimize physical and process waste and (2) to improve the generation of value for the client. The key aspects of a global understanding of Lean in the construction context are [3] culture (competent, flexible, empowered, and committed); technology (last planner system, just in time, value stream mapping, virtual modeling, and others); and philosophy (Lean principles, added value vs. non-added value, and type of wastes). Lean Construction Principles apply both to the total flow process and to its subprocesses; also, the principles implicitly define flow process problems such as complexity, transparency, and segmented control [4]. These principles were summarized in the Introduction and are described in greater detail in Table 1. A comprehensive understanding of these principles is essential to apply Lean correctly in the industry.

Table 1. Koskela's Lean Construction Principles [4].

\begin{tabular}{|c|c|c|}
\hline Id & Name & Description \\
\hline $\mathrm{P}_{1}$ & Reduce waste & $\begin{array}{l}\text { Reduce the share of non-value-adding activities (also called waste). } \\
\text { These include activities that require time, resources, or space but do } \\
\text { not add value for the customer. }\end{array}$ \\
\hline $\mathrm{P}_{2}$ & Increase value & $\begin{array}{l}\text { Increase output value through systematic consideration of customer } \\
\text { requirements. Value is generated through fulfilling customer } \\
\text { requirements, not as an inherent merit of conversion. }\end{array}$ \\
\hline $\mathrm{P}_{3}$ & Reduce variability & $\begin{array}{l}\text { Production processes are variable. There are differences between any } \\
\text { two items, even though they are the same product, and the resources } \\
\text { needed to produce them (time, raw material, labor) vary. }\end{array}$ \\
\hline $\mathrm{P}_{4}$ & Reduce time & $\begin{array}{l}\text { Time is a natural metric for flow processes. A production flow can be } \\
\text { characterized by cycle time, which refers to the time required for a } \\
\text { particular piece of material to traverse the flow. }\end{array}$ \\
\hline $\mathrm{P}_{5}$ & Simplify steps & $\begin{array}{l}\text { Simplification can be understood as reducing the number of } \\
\text { components in a product or reducing the number of steps in a } \\
\text { material or information flow. }\end{array}$ \\
\hline $\mathrm{P}_{6}$ & Increase flexibility & $\begin{array}{l}\text { Practical approaches to increasing flexibility include minimizing lot } \\
\text { sizes to closely match demand, reducing the difficulty of setups, } \\
\text { and customizing as late in the process as possible. }\end{array}$ \\
\hline $\mathrm{P}_{7}$ & Focus on the whole process & $\begin{array}{l}\text { Focus control on the complete process. Segmented flow control } \\
\text { poses a risk of sub-optimization. }\end{array}$ \\
\hline $\mathrm{P}_{8}$ & Increase transparency & $\begin{array}{l}\text { Lack of process transparency increases the propensity to err, reduces } \\
\text { the visibility of errors, and diminishes motivation for improvement. } \\
\text { Build continuous improvement into the process. The effort to reduce }\end{array}$ \\
\hline $\mathrm{P}_{9}$ & Kaizen & $\begin{array}{l}\text { waste and to increase value is an internal, incremental, and iterative } \\
\text { activity that can and must be carried out continuously. }\end{array}$ \\
\hline $\mathrm{P}_{10}$ & Balance flow and conversion & $\begin{array}{c}\text { Balance flow improvement with conversion improvement. } \\
\text { The crucial issue is that flow improvement and conversion } \\
\text { improvement are intimately interconnected. }\end{array}$ \\
\hline$P_{11}$ & Benchmark & $\begin{array}{l}\text { Unlike technology for conversions, the best flow processes are not } \\
\text { marketed; each organization has to find world-class processes } \\
\text { themselves. Benchmarking includes knowing the process } \\
\text { (strengths and weaknesses), knowing industry leaders (finding, } \\
\text { understanding and comparing), and incorporating the best practices. }\end{array}$ \\
\hline
\end{tabular}

The activities that do not add value (also called waste) must be identified, analyzed, and eliminated from work processes. The seven forms of waste under the Lean system were originally conceived in Japan with the inefficiencies of manufacturing in mind, but they also apply to the construction industry. These wastes are as follows: (1) transportation, (2) unnecessary inventory, (3) unnecessary motion, (4) waiting, (5) overproduction, (6) over-processing, and (7) defects [36]. Recently, an eighth waste has been defined for construction [37]: "making-do," a situation where a task is begun without all of its 
standard inputs, or the execution of a task is continued even though the availability of at least one standard input has ceased.

\section{Research Process}

To achieve the objective of this study, the research process comprises five steps: (1) definition and contextualization of the case study; (2) design and planning of four learning activities; (3) implementation of these activities; (4) assessment of the level of understanding of LCPs for each activity; and finally, (5) analysis of the understanding and impact of each learning activity (Figure 1).
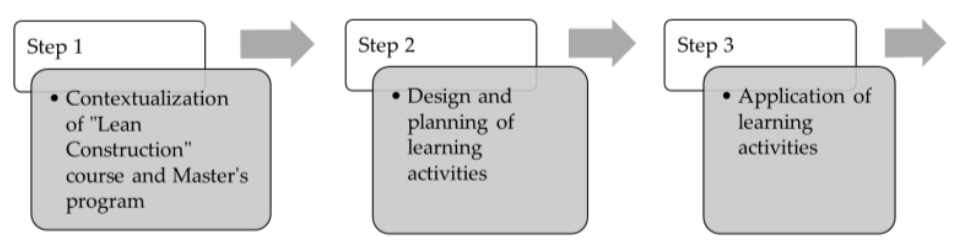

Figure 1. Research process.

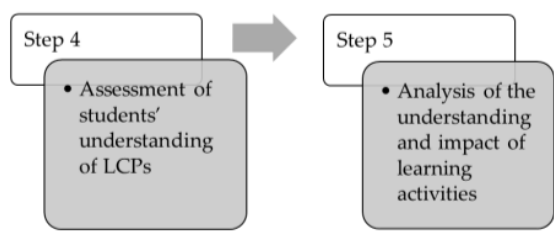

\subsection{Contextualization}

The case study was carried out in the "Lean Construction" course of the Master of Planning and Management in Civil Engineering program of the Universitat Politècnica de València, Spain, in the academic year 2018-2019. Lean Construction is offered as a 3 ECTS elective graduate course. Note that ECTS (European Credit Transfer and Accumulation System) expresses the volume of learning based on the defined learning outcomes and their associated workload [38]. Sixty ECTS credits are allocated to the learning outcomes and associated workload of a full-time academic year; in most cases, workload ranges from 1500 to $1800 \mathrm{~h}$ for an academic year, which means that one credit corresponds to 25 to $30 \mathrm{~h}$ of work [38]. The syllabus of the course has been evolving since 2011, incorporating feedback from the students [19,39]; currently, it covers the topics of historical evolution, waste and flow, value stream mapping, pull management, integrated project delivery, construction planning and control using the Last Planner System, and specific techniques such as 5S, Kan-Ban, and A3 report, among others.

The students in this Master's program are civil engineers and architects from various countries of America, Europe, and Asia; in the 2018-2019 class, there are 20 students from 10 different countries enrolled in the Lean Construction course. The professional experience of the students varies from 0 to 11 years of practice. Figure 2 presents a box chart of the years of experience of the students in this class, who have an average of 3.8 years of professional practice in the AEC industry. Figure 3 illustrates students' previous knowledge and/or experience in Lean Construction: "no" means that the student has no knowledge and/or experience in Lean Construction; "low" means that the student has a low level of knowledge and/or experience; "medium" means that the student has a medium level of knowledge and/or experience; and "high" means that the student has a high level of knowledge and/or experience. Students were clustered around the lowest knowledge levels (85\% of the students did not know anything about Lean). Therefore, the students' diverse countries of origin, large range of professional experience, and similar lack of Lean background made this class a good sample for this research. 


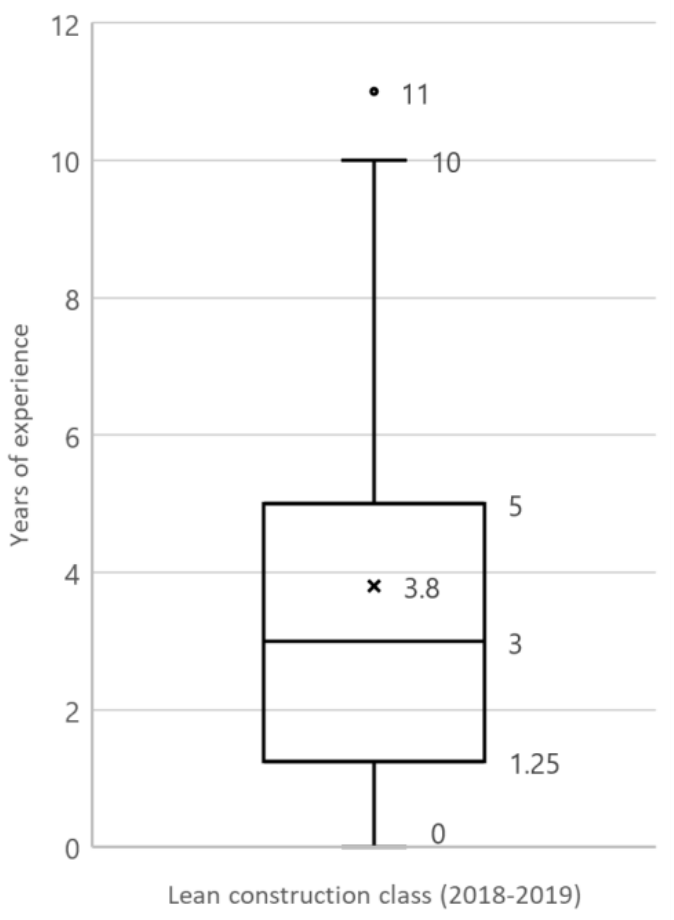

Figure 2. Students' experience in the Architecture, Engineering and Construction (AEC) industry (in years).

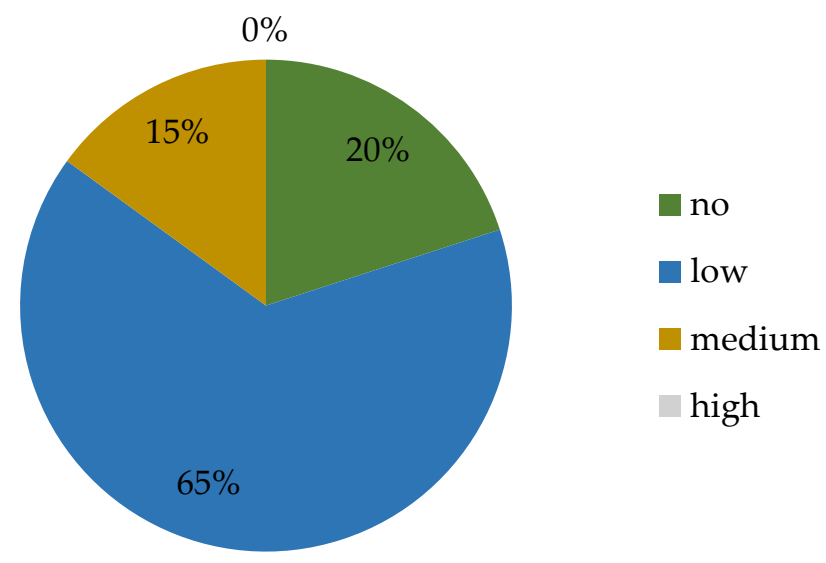

Figure 3. Students' prior level of knowledge and experience in Lean Construction.

\subsection{Design and Planning of Learning Activities}

With the objective that the students would understand and visualize how to implement the principles of Lean Construction in the AEC industry, a longitudinal qualitative approach is assumed [40-42]. This method allows analyzing change (in this case the level of understanding of LCP by students) through a short period of time (three weeks) [40]. This way, four learning activities were designed and implemented in three sessions, each two hours in duration [41]. The selection of these learning activities was based on the following criteria: (1) the activity could be performed in less than $2 \mathrm{~h}$ (regular session time); (2) the required material is low-cost and easily accessible; and (3) none of the activities cover all of the LCPs in-depth. The activities were ordered from the most abstract to the most realistic.

First, an introductory two-hour lecture session was used to highlight the basic theory, principles, and history of Lean Management and Lean Construction. Then, in the following sessions, GBL was used as the teaching method to help students understand the LCPs and how to apply them [26,27]. The games were ordered from the most abstract thought and systemic thinking ("broken square" game), to the simulation of processes with tangible material ("make a card" simulation game), followed by the 
application of the principles in a real situation ("work sampling" game). Figure 4 shows the sequence of activities and a brief description of each. After each learning activity, the students answered a survey to measure the degree of understanding of each LCP.

\begin{tabular}{|c|c|c|c|c|}
\hline Class'style & Lecture class & \multicolumn{3}{|c|}{ Game based learning } \\
\hline Activity & $\begin{array}{l}\text { Introduction to } \\
\text { Lean }\end{array}$ & $\begin{array}{l}\text { Broken square } \\
\text { game }\end{array}$ & $\begin{array}{c}\text { Make a card } \\
\text { simulation game }\end{array}$ & $\begin{array}{l}\text { Work sampling } \\
\text { game }\end{array}$ \\
\hline $\begin{array}{l}\text { Main } \\
\text { students' } \\
\text { purpose }\end{array}$ & $\begin{array}{l}\text { Contextualize Lean } \\
\text { construction: history, } \\
\text { theory and } \\
\text { principles }\end{array}$ & $\begin{array}{l}\text { Understand the } \\
\text { importance of } \\
\text { communication and } \\
\text { systemic thinking }\end{array}$ & $\begin{array}{l}\text { Understand the } \\
\text { continuous } \\
\text { improvement: } \\
\text { standardization, } \\
\text { pull-system and } \\
\text { collaboration }\end{array}$ & $\begin{array}{l}\text { Analyze value- } \\
\text { added, contributory } \\
\text { and non- } \\
\text { contributory } \\
\text { activities }\end{array}$ \\
\hline Materials & Presentation file & $\begin{array}{l}\text { Paper, and broken } \\
\text { square template, } \\
\text { presentation file }\end{array}$ & $\begin{array}{c}\text { Paper, adhesive labels } \\
\text { (2 colors rectangular } \\
\& 1 \text { color circle), pen } \\
\text { presentation file }\end{array}$ & $\begin{array}{c}\text { Construction site } \\
\text { recording, Excel file } \\
\text { template, } \\
\text { presentation file }\end{array}$ \\
\hline Time & 120 minutes & 45 minutes & 75 minutes & 120 minutes \\
\hline
\end{tabular}

Figure 4. Lean learning activities.

\subsection{Application of Learning Activities}

\subsubsection{Game 1: "Broken Square" Game}

The broken square game was proposed by Bavela [43] and has been used mainly as a tool to foster communication, collaboration, and cooperation among different people with a common goal [44]. In this game, the students are grouped in teams of five. Each student is provided with an envelope with different pieces that can be assembled to form a square. The team is given the following mission: each team member must assemble a square of the same dimensions as his/her teammates within $10 \mathrm{~min}$. Team members are not allowed to communicate (not talking, pointing or any other kind of communication); after no team achieves the mission, the students are able to communicate to fulfill the mission. Finally, the activity ends with a reflection on what has been learned [45]. The learning objective of this game is that students are able to understand the importance of communication and systemic thinking in work processes.

\subsubsection{Game 2: "Make a Card" Simulation}

This game is a simulation to demonstrate the advantages of Kanban and Pull over traditional Batch and Push [46]. Alarcon's adaptation of this game is used, which is described in detail by Brioso [34]. In general terms, students are grouped in teams of six in a work chain: each student is assigned to a work station where he or she has a specific task; together they must create a paper card with a standard design using colored adhesive labels. The game is divided into three rounds of six minutes. In the first round, (1) students cannot communicate, (2) they must maintain position, (3) each station delivers batches of 5 cards to the next in an inventory space, (4) batches are not quality-certified until the end of the six stations, (5) workers can only do their own work, and (6) each worker is paid for their work per unit produced. In the second round, the process is the same, but the following changes are made: (1) the batches are one card and workers can only start creating if the next station has empty inventory (pull system); (2) workers can communicate quality problems; and (3) each worker is paid per hour with a bonus for team performance. The third round maintains the same basic process but the following changes are made: (1) workers can balance the workload between stations; 
(2) workers can solve detected quality problems themselves; and (3) there is total communication. In each round, the following indicators are calculated: number of cards produced, cycle time per card, rework for quality, and work in progress; therefore, the usefulness of each work station and of the entire system is calculated. The learning objective of this game is that students are able to understand the importance of continuous improvement (kaizen), standardization, the pull system, batch reduction and collaborative work.

\subsubsection{Game 3: “Work Sampling" Game}

The work sampling game is an activity adapted by the authors in which the work sampling technique is applied to a real construction project. This technique was first developed in the industrial engineering field as a work measurement tool to control inputs; then in the 1960s, it was adapted to the construction industry to assess productivity [47]. Currently, work sampling is being used by a few large construction companies as a means to benchmark direct-work rates so that improvements can be made [48]. In this game, students have to identify and analyze the work of a construction site, categorizing activities as those that add value, or productive work (PW); support activities, or contributing work (CW); and non-contributing work (NCW). The latter two are further classified into the established Lean wastes (waiting, transportation, inventory, motion, etc.). The students identify the type of work from a video recorded (30 min) from an Unmanned Aerial Vehicle (UAV) of a construction site of a high-rise building where there are approximately 80 workers; the goal is to obtain between 80 and 100 observations. Then, added to a previous database provided by the instructor, the students do the following: calculate the percentages of $\mathrm{PW}, \mathrm{CW}$, and NCW; perform statistical validation of the sample; and analyze more frequent wastes using Pareto diagrams. Finally, the students share their results with the whole class in order to establish an internal benchmark between the different observers. The instructor presents typical values of PW, CW, and NCW for different types of projects, so that the students benchmark between the observed project and the AEC industry. The learning objectives of this game are that students are able to analyze value-added, contributory and non-contributory activities and to perform internal and external benchmarks.

\subsection{Assessment of Students' Understanding of Lean Construction Principles}

In order to analyze the evolution of the students' competence associated with each LCP, a self-assessment was carried out at the beginning and the end of each game. A questionnaire was defined to assess the suitability of each game for learning about and understanding each of Koskela's eleven principles [4]. The questionnaire was divided into four parts:

1. Characterization of the respondents (4 questions): country of origin, bachelor's degree, years of professional experience, and prior level of knowledge and/or experience about Lean Construction.

2. Assessment of competence regarding Koskela's eleven principles [4] before starting the course.

3. Assessment of the competence acquired after attending the lecture class and participating in each game.

4. Students' perception about the best game for acquiring the maximum competence in each LCP. These comments are later used to validate the results obtained in part 2.

The assessment of competence in parts 2 and 3 was graded along a Likert scale from 1 to 5 :

- 1 means that the student did not understand the theoretical approach of the LCP and its application in the construction industry.

- 2 means that the student reached a medium level of understanding of the theoretical approach of the LCP; however, the student did not understand its applicability in the construction industry.

- 3 means that the student fully understood the theoretical approach of the LCP; however, the student did not understand its applicability in the construction industry.

- 4 means that the student fully understood the theoretical approach of the LCP but did not fully understand its applicability in the construction industry. 
- 5 means that the student fully understood the theoretical approach of the LCP and its applicability in the construction industry.

\subsection{Analysis of the Understanding and Impact of Each Learning Activity}

The questionnaires were answered by the students, and the results were analyzed using IBM SPSS Statistics. According to the longitudinal qualitative approach, change has to be measured after every episode (or learning activity in this study) [40,41]. The analysis used descriptive statistics to characterize the sample and to observe the increase in understanding of each LCP after each class. The reliability of the collected responses from the students was evaluated with Cronbach's alpha analysis. Ranging from 0 to 1 , a value of Cronbach's alpha over 0.70 represents good internal consistency or reliability of a sample. The Mann-Whitney U-test was undertaken to analyze whether the students' professional expertise has a significant influence $(p$-value $>0.05)$ on the level of acquired competence after the lecture class. This nonparametric statistical procedure was chosen because the sample size was relatively small and independent, it therefore not being possible to assume that the data were normally distributed [49]. Finally, the Wilcoxon test was performed to analyze whether each game has a significant effect ( $p$-value $<0.05$ ) on the level of competence achieved for each LCP [50]. Finally, the validity of the assessment was performed through the comparison between the answers of part 4 of the questionnaire and the assessments obtained after performing each game.

\section{Results and Discussion}

The level of acquired competence of each student was assessed through the questionnaire. The analysis of the questionnaire revealed that the value of Cronbach's alpha is 0.897 , confirming that the sample is consistent and reliable. The spider plot in Figure 5 shows the median level of competence acquired with respect to each of Koskela's eleven principles [4] after attending the lecture and playing each game [4]. As can be seen, after each activity (lecture, game 1, game 2, and game 3), the level of competence acquired increased until achieving the maximum score (5) for each principle. However, to achieve a better understanding of the role that each activity plays in the teaching and learning of the eleven LCPs, an in-depth analysis was performed for each activity.

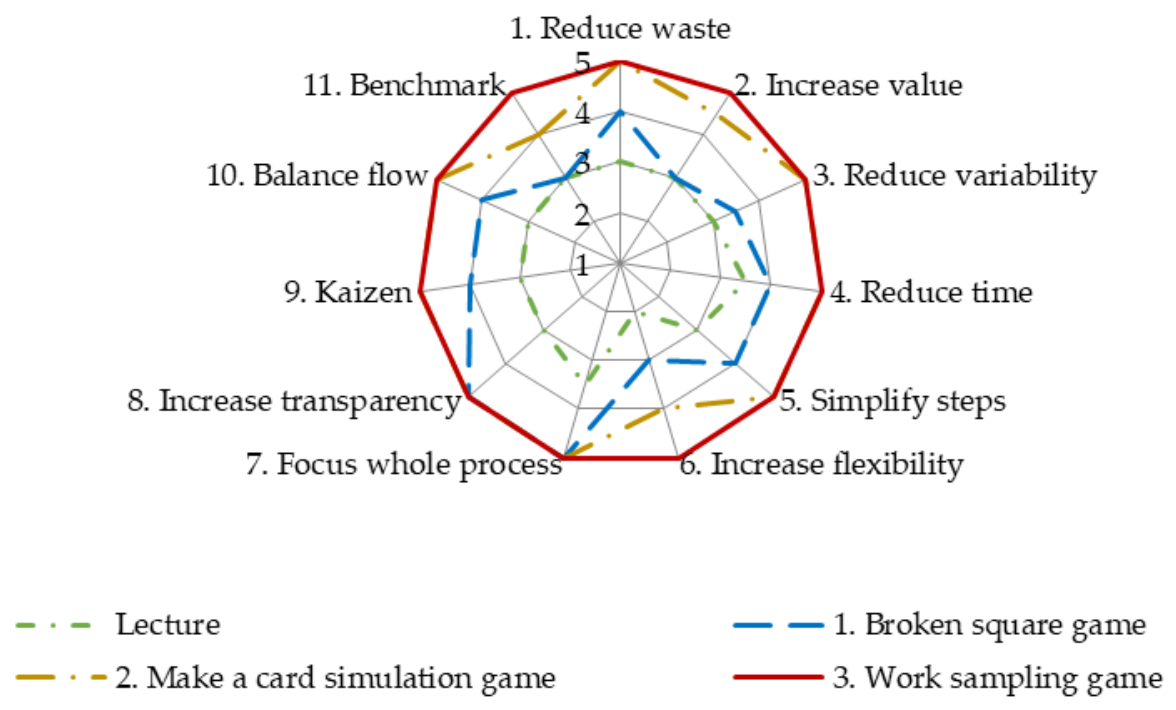

Figure 5. Median level of acquired competence for each principle after the lecture and each game.

\subsection{Session 1: Lecture Class}

The distribution of the assessment values achieved after the lecture class is displayed in Table 2. As can be seen, the median was three for most principles, four for $\mathrm{P}_{4}$ (reduce time) and $\mathrm{P}_{7}$ (focus on the whole process), and two for $\mathrm{P}_{6}$ (increase flexibility). These results represent that the lecture class 
was appropriate for explaining the theoretical approach associated with each principle, because, in general, the level of knowledge acquired was high for the eleven principles. However, the lecture class was not effective at helping students to understand the applicability of most of the LCPs, as only $\mathrm{P}_{4}$ (reduce time) and $\mathrm{P}_{7}$ (focus on the whole process) obtained medians equal to 4 (medium level of understanding about the principle's application) and $\mathrm{P}_{2}$ (increase value) and $\mathrm{P}_{3}$ (reduce variability) were assessed with scores of 1,2 , and 3 by most of the students (no understanding about its application). This result is in line with those of previous authors [29,51-53] who have highlighted the importance of involving more experiential techniques such as simulations and games to teach LCPs.

Table 2. Distribution of assessment values achieved after the lecture class.

\begin{tabular}{cccccccccccc}
\hline \multirow{2}{*}{ Statistics } & \multicolumn{10}{c}{ Lean Construction Principles } \\
\cline { 2 - 12 } & $\mathbf{P}_{\mathbf{1}}$ & $\mathbf{P}_{\mathbf{2}}$ & $\mathbf{P}_{\mathbf{3}}$ & $\mathbf{P}_{\mathbf{4}}$ & $\mathbf{P}_{\mathbf{5}}$ & $\mathbf{P}_{\mathbf{6}}$ & $\mathbf{P}_{\mathbf{7}}$ & $\mathbf{P}_{\mathbf{8}}$ & $\mathbf{P}_{\mathbf{9}}$ & $\mathbf{P}_{\mathbf{1 0}}$ & $\mathbf{P}_{\mathbf{1 1}}$ \\
\hline Median & 3.00 & 3.00 & 3.00 & 3.50 & 3.00 & 2.00 & 3.50 & 3.00 & 3.00 & 3.00 & 3.00 \\
\hline Minimum & 2.00 & 1.00 & 1.00 & 2.00 & 2.00 & 1.00 & 2.00 & 2.00 & 1.00 & 1.00 & 1.00 \\
\hline Maximum & 5.00 & 4.00 & 5.00 & 5.00 & 5.00 & 4.00 & 5.00 & 5.00 & 5.00 & 5.00 & 5.00 \\
\hline 25th percentile & 2.25 & 2.00 & 2.00 & 3.00 & 2.00 & 2.00 & 3.00 & 3.00 & 2.00 & 2.00 & 2.00 \\
\hline 50th percentile & 3.00 & 3.00 & 3.00 & 3.50 & 3.00 & 2.00 & 3.50 & 3.00 & 3.00 & 3.00 & 3.00 \\
\hline 75th percentile & 4.00 & 3.00 & 4.00 & 4.75 & 4.00 & 3.00 & 4.00 & 4.00 & 4.00 & 4.00 & 4.00 \\
\hline
\end{tabular}

As Deif [32] and Nofera et al. [20] have claimed, although the lecture class helps students to understand the theoretical approach, their level of understanding of LCPs could depend on their professional experience; thus, the Mann-Whitney U-test was conducted to evaluate whether the level of acquired competence after the lecture class depends on the number of years of the students' professional expertise. The results in Table 3 show that the professional expertise does not have a significant influence on the level of competence acquired after the lecture class ( $p$-value $<0.05)$. Therefore, these results highlight the need to use game-based learning to teach Lean Construction Principles in order to achieve a proper understanding of their applicability in the construction industry [54].

Table 3. Influence of professional expertise on the level of acquired competence after the lecture class.

\begin{tabular}{cccccccccccc}
\hline \multirow{2}{*}{ Statistics } & \multicolumn{10}{c}{ Lean Construction Principles } \\
\cline { 2 - 13 } & $\mathbf{P}_{\mathbf{1}}$ & $\mathbf{P}_{\mathbf{2}}$ & $\mathbf{P}_{\mathbf{3}}$ & $\mathbf{P}_{\mathbf{4}}$ & $\mathbf{P}_{\mathbf{5}}$ & $\mathbf{P}_{\mathbf{6}}$ & $\mathbf{P}_{\mathbf{7}}$ & $\mathbf{P}_{\mathbf{8}}$ & $\mathbf{P}_{\mathbf{9}}$ & $\mathbf{P}_{\mathbf{1 0}}$ & $\mathbf{P}_{\mathbf{1 1}}$ \\
\hline Mann-Whitney U & 43.000 & 41.000 & 41.000 & 38.000 & 42.000 & 36.500 & 40.000 & 43.000 & 24.000 & 36.000 & 37.000 \\
\hline$p$-value & 0.682 & 0.574 & 0.573 & 0.411 & 0.623 & 0.335 & 0.520 & 0.669 & 0.055 & 0.337 & 0.379 \\
\hline
\end{tabular}

\subsection{Session 2: "Broken Square" Game}

The learning objective of the "broken square" game (game 1) was to understand the importance of communication and systemic thinking in work processes [44]. To analyze the significant effect ( $p$-value $<0.05$ ) of the "broken square" game on the level of competence achieved for each LCP, the Wilcoxon test was performed. Table 4 shows that playing this game entails a significant effect on the understanding of each principle.

Table 4. Significant differences before and after performing the "broken square" game.

\begin{tabular}{ccccccccccccc}
\hline \multirow{2}{*}{ Wilcoxon Test } & \multicolumn{10}{c}{ Lean Construction Principles } \\
\cline { 2 - 13 } & $\mathbf{P}_{\mathbf{1}}$ & $\mathbf{P}_{\mathbf{2}}$ & $\mathbf{P}_{\mathbf{3}}$ & $\mathbf{P}_{\mathbf{4}}$ & $\mathbf{P}_{\mathbf{5}}$ & $\mathbf{P}_{\mathbf{6}}$ & $\mathbf{P}_{\mathbf{7}}$ & $\mathbf{P}_{\mathbf{8}}$ & $\mathbf{P}_{\mathbf{9}}$ & $\mathbf{P}_{\mathbf{1 0}}$ & $\mathbf{P}_{\mathbf{1 1}}$ \\
\hline$p$-value & 0.002 & 0.001 & 0.002 & 0.002 & 0.003 & 0.006 & 0.001 & 0.000 & 0.001 & 0.002 & 0.006 \\
\hline
\end{tabular}


Additionally, Figure 5 shows the medians for each Lean principle before and after playing this game. As can be seen, there are increases in the medians values for each principle except for $\mathrm{P}_{2}$ (increase value) and $\mathrm{P}_{11}$ (benchmark). $\mathrm{P}_{8}$ (increase transparency) experienced the greatest increase, and in conjunction with $\mathrm{P}_{4}$ (reduce time) and $\mathrm{P}_{7}$ (focus on the whole process) achieved the maximum value for the median (5). The median competence value for most of the principles after this game was four. However, these results did not represent all students in the sample.

Table 5 shows the distribution of assessment values for each principle after playing game 1 . As can be seen, $\mathrm{P}_{4}$ (reduce time), $\mathrm{P}_{7}$ (focus on the whole process), and $\mathrm{P}_{8}$ (increase transparency) were assessed values of four and five by most of the students. However, the median values for $\mathrm{P}_{2}$ (increase value), $\mathrm{P}_{6}$ (increase flexibility), and $\mathrm{P}_{11}$ (benchmark) were equal to three, having received scores of one and two from some of the students. Thus, although in general, the "broken square" game shows good results for understanding the applicability of most of the LCPs, this game should be used when the principle $\mathrm{P}_{8}$ is to be enforced, highlighting the importance of communication and systemic thinking in work processes.

Table 5. Distribution of assessment values achieved after the "broken square" game.

\begin{tabular}{|c|c|c|c|c|c|c|c|c|c|c|}
\hline \multirow{2}{*}{ Statistics } & \multicolumn{10}{|c|}{ Lean Construction Principles } \\
\hline & $\mathbf{P}_{2}$ & $\mathbf{P}_{3}$ & $\mathbf{P}_{4}$ & $\mathbf{P}_{5}$ & $\mathbf{P}_{6}$ & $\mathbf{P}_{7}$ & $\mathbf{P}_{8}$ & $\mathbf{P}_{9}$ & $\mathbf{P}_{10}$ & $\mathbf{P}_{11}$ \\
\hline Median 4.00 & 3.00 & 3.50 & 4.00 & 4.00 & 3.00 & 5.00 & 5.00 & 4.00 & 4.00 & 3.00 \\
\hline Minimum 2.00 & 1.00 & 2.00 & 3.00 & 2.00 & 1.00 & 3.00 & 3.00 & 2.00 & 2.00 & 2.00 \\
\hline Maximum5.00 & 5.00 & 5.00 & 5.00 & 5.00 & 5.00 & 5.00 & 5.00 & 5.00 & 5.00 & 5.00 \\
\hline percentile 3.00 & 3.00 & 3.00 & 4.00 & 3.00 & 2.00 & 4.00 & 4.00 & 3.00 & 3.25 & 3.00 \\
\hline $\begin{array}{l}\text { 50th } \\
\text { percentile }\end{array}$ & 3.00 & 3.50 & 4.00 & 4.00 & 3.00 & 5.00 & 5.00 & 4.00 & 4.00 & 3.00 \\
\hline $\begin{array}{l}\text { 75th } \\
\text { percentile }\end{array}$ & 4.00 & 4.00 & 5.00 & 4.00 & 4.00 & 5.00 & 5.00 & 4.75 & 4.00 & 4.00 \\
\hline
\end{tabular}

\subsection{Session 3: "Make a Card" Game}

The aim of the "make a card" game (game 2) is to make students think about how changes in a production system impact its productivity [34]. Table 6 shows the results of the Wilcoxon test, which analyzes the significant effect ( $p$-value $<0.05$ ) of this game on the level of competence achieved for each LCP. As can be seen, the game has a significant effect on the understanding of each principle.

Table 6. Significant differences before and after performing the "make a card" game.

\begin{tabular}{ccccccccccccc}
\hline \multirow{2}{*}{$\begin{array}{c}\text { Wilcoxon } \\
\text { Test }\end{array}$} & $\mathbf{P}_{\mathbf{1}}$ & $\mathbf{P}_{\mathbf{2}}$ & $\mathbf{P}_{\mathbf{3}}$ & $\mathbf{P}_{\mathbf{4}}$ & $\mathbf{P}_{\mathbf{5}}$ & $\mathbf{P}_{\mathbf{6}}$ & $\mathbf{P}_{\mathbf{7}}$ & $\mathbf{P}_{\mathbf{8}}$ & $\mathbf{P}_{\mathbf{9}}$ & $\mathbf{P}_{\mathbf{1 0}}$ & $\mathbf{P}_{\mathbf{1 1}}$ \\
\hline$p$-value & 0.000 & 0.000 & 0.000 & 0.000 & 0.000 & 0.000 & 0.024 & 0.019 & 0.000 & 0.001 & 0.004 \\
\hline
\end{tabular}

Additionally, Figure 5 shows the changes with respect to the median values for each Lean principle before and after playing game 2 . The median values for most of the principles were equal to 5 . The most important increase was associated with $\mathrm{P}_{2}$ (increase value). Only $\mathrm{P}_{6}$ (increase flexibility) and $\mathrm{P}_{11}$ (benchmark) did not achieve a median equal to five. These results are presented in greater detail in Table 7. This shows the distribution of assessment values after the game, taking into account the scores reported by each student. Principles $\mathrm{P}_{3}$ (reduce variability), $\mathrm{P}_{4}$ (reduce time), $\mathrm{P}_{7}$ (focus on the whole process), $\mathrm{P}_{8}$ (increase transparency), and $\mathrm{P}_{10}$ (balance flow and conversion) mainly obtained values equal to five. This represents that the combination of the lecture class with the first two games helped to teach about these principles in an effective way. The largest increase was obtained for $\mathrm{P}_{2}$ 
(increase value). However, although the "make a card" game had a strong influence on understanding this principle, some students still assigned values of two or three to $P_{2}$, claiming a lack of understanding about its applicability in the construction industry. On the other hand, small differences can be highlighted with respect to $\mathrm{P}_{6}$ (increase flexibility), since students assessed their acquired competence mainly with values equal to two and three.

Table 7. Distribution of assessment values achieved after the "make a card" game.

\begin{tabular}{cccccccccccc}
\hline \multirow{2}{*}{ Statistics } & \multicolumn{10}{c}{ Lean Construction Principles } \\
\cline { 2 - 12 } & $\mathbf{P}_{\mathbf{1}}$ & $\mathbf{P}_{\mathbf{2}}$ & $\mathbf{P}_{\mathbf{3}}$ & $\mathbf{P}_{\mathbf{4}}$ & $\mathbf{P}_{\mathbf{5}}$ & $\mathbf{P}_{\mathbf{6}}$ & $\mathbf{P}_{\mathbf{7}}$ & $\mathbf{P}_{\mathbf{8}}$ & $\mathbf{P}_{\mathbf{9}}$ & $\mathbf{P}_{\mathbf{1 0}}$ & $\mathbf{P}_{\mathbf{1 1}}$ \\
\hline Median & 5.00 & 4.50 & 5.00 & 5.00 & 5.00 & 4.00 & 5.00 & 5.00 & 5.00 & 5.00 & 4.00 \\
\hline Minimum & 4.00 & 2.00 & 3.00 & 4.00 & 4.00 & 2.00 & 4.00 & 4.00 & 4.00 & 4.00 & 2.00 \\
\hline Maximum & 5.00 & 5.00 & 5.00 & 5.00 & 5.00 & 5.00 & 5.00 & 5.00 & 5.00 & 5.00 & 5.00 \\
\hline 25th percentile & 4.25 & 4.00 & 5.00 & 5.00 & 4.00 & 3.00 & 5.00 & 5.00 & 4.25 & 5.00 & 4.00 \\
\hline 50th percentile & 5.00 & 4.50 & 5.00 & 5.00 & 5.00 & 4.00 & 5.00 & 5.00 & 5.00 & 5.00 & 4.00 \\
\hline 75th percentile & 5.00 & 5.00 & 5.00 & 5.00 & 5.00 & 5.00 & 5.00 & 5.00 & 5.00 & 5.00 & 5.00 \\
\hline
\end{tabular}

\subsection{Session 4: "Work Sampling" Game}

The learning objective of the "work sampling" game (game 3) was to analyze value-added, contributory, and non-contributory activities and establish an internal and external benchmark [47,48]. Table 8 shows that, after this game, the median assessment scores for $\mathrm{P}_{6}$ (increase flexibility) and $\mathrm{P}_{11}$ (benchmark) obtained values of five, with the result that the medians for all principles reached the maximum value. The inclusion of this third game enforced the level of knowledge and understanding of the applicability of the eleven LCPs in the construction industry. Although some scores associated with the principles $\mathrm{P}_{2}$ (increase value) and $\mathrm{P}_{6}$ (increase flexibility) did not improve, since several students assigned them values equal to two and three, the significant influence that the "work sampling" game had on most of the principles is highlighted in Table 8 , since the assessment values are mainly concentrated between four and five.

Table 8. Distribution of assessment values achieved after the "work sampling" game.

\begin{tabular}{cccccccccccc}
\hline \multirow{2}{*}{ Statistics } & \multicolumn{10}{c}{ Lean Construction Principles } \\
\cline { 2 - 11 } & $\mathbf{P}_{\mathbf{1}}$ & $\mathbf{P}_{\mathbf{2}}$ & $\mathbf{P}_{\mathbf{3}}$ & $\mathbf{P}_{\mathbf{4}}$ & $\mathbf{P}_{\mathbf{5}}$ & $\mathbf{P}_{\mathbf{6}}$ & $\mathbf{P}_{\mathbf{7}}$ & $\mathbf{P}_{\mathbf{8}}$ & $\mathbf{P}_{\mathbf{9}}$ & $\mathbf{P}_{\mathbf{1 0}}$ & $\mathbf{P}_{\mathbf{1 1}}$ \\
\hline Median & 5.00 & 5.00 & 5.00 & 5.00 & 5.00 & 5.00 & 5.00 & 5.00 & 5.00 & 5.00 & 5.00 \\
\hline Minimum & 4.00 & 2.00 & 4.00 & 4.00 & 4.00 & 2.00 & 4.00 & 4.00 & 4.00 & 4.00 & 4.00 \\
\hline Maximum & 5.00 & 5.00 & 5.00 & 5.00 & 5.00 & 5.00 & 5.00 & 5.00 & 5.00 & 5.00 & 5.00 \\
\hline 25th percentile & 5.00 & 4.00 & 5.00 & 5.00 & 5.00 & 3.25 & 5.00 & 5.00 & 5.00 & 5.00 & 4.00 \\
\hline 50th percentile & 5.00 & 5.00 & 5.00 & 5.00 & 5.00 & 5.00 & 5.00 & 5.00 & 5.00 & 5.00 & 5.00 \\
\hline 75th percentile & 5.00 & 5.00 & 5.00 & 5.00 & 5.00 & 5.00 & 5.00 & 5.00 & 5.00 & 5.00 & 5.00 \\
\hline
\end{tabular}

In order to achieve a deep understanding about the influence of the third game on the acquired competences, the Wilcoxon Test was performed to assess the significance of differences with respect to the level of competence acquired before and after performing this activity. Table 9 shows the $p$-value obtained for each principle. Only $\mathrm{P}_{1}$ (reduce waste), $\mathrm{P}_{6}$ (increase flexibility), and $\mathrm{P}_{11}$ (benchmark) showed significant differences ( $p$-value $<0.05$ ). 
Table 9. Significant differences before and after performing the "work sampling" game.

\begin{tabular}{ccccccccccccc}
\hline \multirow{2}{*}{ Wilcoxon Test } & \multicolumn{10}{c}{ Lean Construction Principles } \\
\cline { 2 - 13 } & $\mathbf{P}_{\mathbf{1}}$ & $\mathbf{P}_{\mathbf{2}}$ & $\mathbf{P}_{\mathbf{3}}$ & $\mathbf{P}_{\mathbf{4}}$ & $\mathbf{P}_{\mathbf{5}}$ & $\mathbf{P}_{\mathbf{6}}$ & $\mathbf{P}_{\mathbf{7}}$ & $\mathbf{P}_{\mathbf{8}}$ & $\mathbf{P}_{\mathbf{9}}$ & $\mathbf{P}_{\mathbf{1 0}}$ & $\mathbf{P}_{\mathbf{1 1}}$ \\
\hline$p$-value & 0.046 & 0.083 & 0.157 & 0.157 & 0.083 & 0.014 & 0.157 & 0.157 & 0.083 & 0.157 & 0.006 \\
\hline
\end{tabular}

Finally, to validate the results associated with each game, students were asked about the best game to acquire competence for each Lean principle (see Figure 6). As can be seen, the "broken square" game plays an important role in learning about focusing control on the complete process $\left(\mathrm{P}_{7}: 40 \%\right)$ and increasing process transparency $\left(\mathrm{P}_{8}: 60 \%\right)$; the "make a card" game influences most of the principles, being strongly significant for learning about reducing the cycle time (P4: 70\%), balance flow improvement with conversion improvement $\left(\mathrm{P}_{10}: 70 \%\right)$, reducing variability $\left(\mathrm{P}_{3}: 65 \%\right)$, building continuous improvement into the process $\left(\mathrm{P}_{9}: 65 \%\right)$, increasing output value through systematic consideration of customer requirements $\left(\mathrm{P}_{2}: 55 \%\right)$, simplifying by minimizing the number of steps, parts and linkages $\left(\mathrm{P}_{5}: 55 \%\right)$, and increasing output flexibility $\left(\mathrm{P}_{6}: 55 \%\right)$. Finally, the "work sampling" game is important to acquire competence on benchmarking $\left(\mathrm{P}_{11}: 45 \%\right)$.

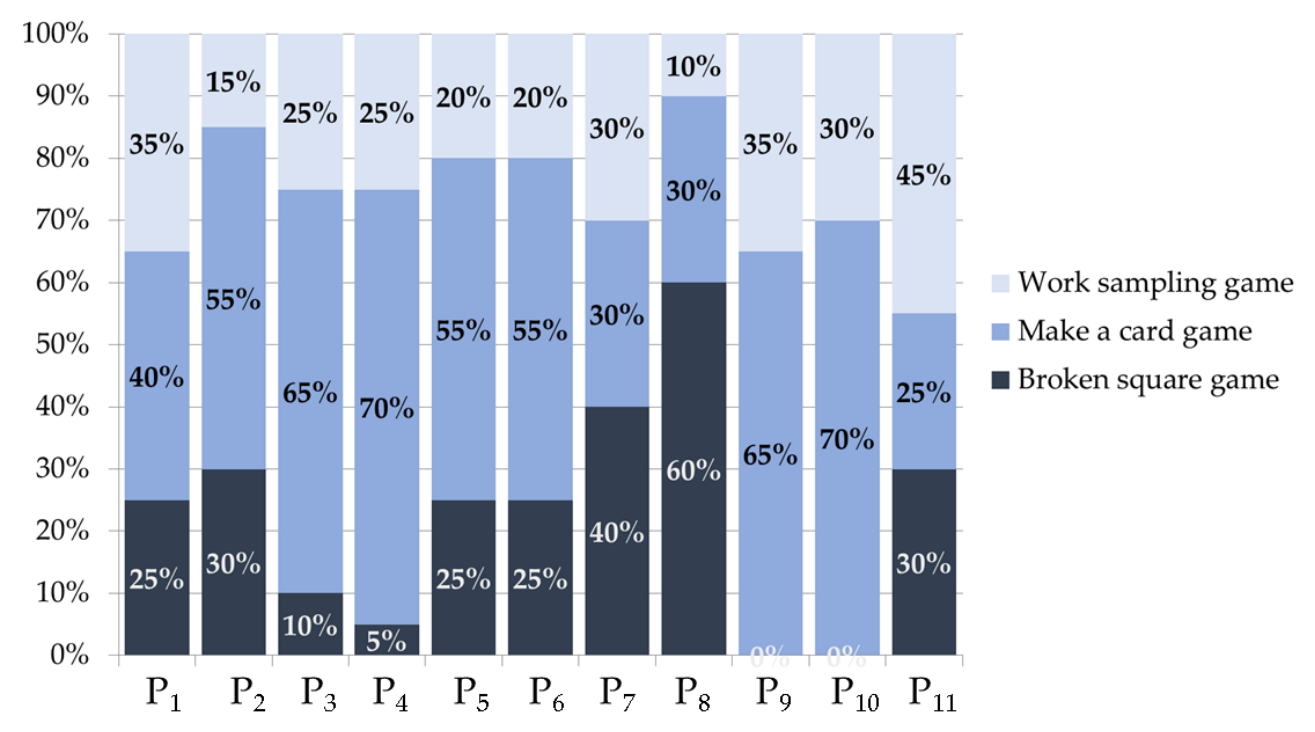

Figure 6. Game preference of the students to learn each principle.

Overall, these results highlight the need to combine lecture with multiple games to achieve both comprehensive knowledge about Lean principles and understanding of their application in the construction industry $[14,29,54]$. Additionally, following Burch and Smith [16], the results emphasize the importance of choosing specific simulations and games depending on the particular LCPs to be taught, ensuring the success of learning.

\section{Conclusions}

This study evaluated a combination of traditional lecture and three games ("broken square," "make a card," and "work sampling") as a pedagogical approach to teach the Lean Construction Principles (LCPs) and their application in the construction industry. This paper aims to show the impact of each activity on the understanding of LCPs.

The lecture class was effective at teaching the theoretical approach associated with each Lean principle. However, the results highlighted that most students did not attain a clear perspective about the applicability of the Lean principles in the construction industry through the lecture class, resulting in the need to combine this technique with games to meet that goal. The results of the 
Mann-Whitney U-test indicated that this understanding did not depend on the professional expertise of the students. Practically, the three games showed a significant effect on the understanding of the eleven LCPs. However, the "broken square" game was especially effective at teaching about increasing transparency in the process $\left(\mathrm{P}_{8}\right)$, reducing the cycle time $\left(\mathrm{P}_{4}\right)$, and focusing control on the complete process $\left(\mathrm{P}_{7}\right)$ by enhancing communication and systemic thinking in work processes; the "make a card" simulation game was particularly important for understanding the applicability of increasing output value through systematic consideration of customer requirements $\left(\mathrm{P}_{2}\right)$ and for deepening students' understanding of the rest of the principles; finally, the "work sampling" game reinforces the level of knowledge and understanding of the applicability of the eleven LCPs, being especially important for understanding the principles of increasing output flexibility $\left(\mathrm{P}_{6}\right)$ and benchmarking $\left(\mathrm{P}_{11}\right)$. Therefore, based on the results of the study, it can be stated that: (1) to guarantee successful learning outcomes for the LCPs, it is recommended to combine the lecture class with multiple games; and, (2) it is key in selecting the games depending on the specific LCP that want to be taught, since not all games are proper to achieve a comprehensive understanding of all the LCPs. These conclusions are crucial for training in Lean Construction.

Even though the analyses conducted for this study have helped to understand the role that each activity (traditional lecture and three simple games) plays in teaching students the theoretical approach and the applicability of each Lean principle in the construction industry, this work is not exempt from limitations, since the sample focused on only one class of students who were of different nationalities and had varying levels of previous knowledge about the LCPs. However, the analysis demonstrated that these factors did not have influence over the results. Consequently, it is recommended to analyze the influence of these factors when assessing the level of knowledge after performing Lean games. Additionally, further research is needed to contribute to a better understanding of what games should be combined with the lecture class to teach about each specific LCP. Future research could focus on combining other games, analyzing the differences when implementing the games in different educational institutions or countries, studying the influence of the national or regional culture on the understanding of the LCPs, and assessing the differences when implementing the games in educational institutions vs. in companies. Above all, activities to teach the LCPs through game-based learning need to be widely studied to optimize the teaching process and maximize the learning results in educational institutions and companies. Besides, these activities can be applied to other disciplines. In this case, it is recommended to adapt the "work sampling" game to a real case related to the particular discipline

Author Contributions: This paper represents the results of teamwork. All of the authors jointly designed the research methodology and carried out the case study. R.F.H., M.A.S., and L.M.-D. analyzed the results. All of the authors jointly worked on the validation. R.F.H., M.A.S., L.M.-D., and T.G.-S. drafted the manuscript. Finally, E.P. reviewed and edited the manuscript.

Funding: This research was funded by CONICYT grant number PCHA/National Doctorate/2018-21180884 for funding the graduate research of Herrera, and by the Spanish Ministry of Economy and Competitiveness, along with FEDER funding, grant number BIA2017-85098-R. The APC was funded by School of Civil Engineering, Pontificia Universidad Católica de Valparaíso, Chile.

Acknowledgments: The authors wish to thank all students participating in this study, as well as Fernando Cervero for the insight provided.

Conflicts of Interest: The authors declare no conflict of interest.

\section{References}

1. Gao, S.; Low, S.P. The Toyota Way model: An alternative framework for lean construction. Total Qual. Manag. Bus. Excell. 2014, 25, 664-682. [CrossRef]

2. González, V.A.; Orozco, F.; Senior, B.; Ingle, J.; Forcael, E.; Alarcón, L.F. LEBSCO: Lean-Based Simulation Game for Construction Management Classrooms. J. Prof. Issues Eng. Educ. Pract. 2015, 141, 4015002. [CrossRef]

3. Salvatierra, J.L.; Alarcón, L.F.; López, Á.; Velásquez, X. Lean diagnosis for chilean construction industry: Towards more sustainable Lean practices and tools. In Proceedings of the 23rd Annual Conference of the International Group for Lean Construction, Perth, Australia, 29-31 July 2015; pp. 642-651. 
4. Koskela, L. Application of the New Production Philosophy to Construction; Standford University: Standford, CA USA, 1992.

5. Alarcón, L.; Pellicer, E. Un nuevo enfoque en la gestión: La construcción sin pérdidas A new management focus: Lean construction. Rev. Obras Públicas Febrero 2009, 496, 45-52.

6. Ballard, G.; Howell, G. Lean project management. Build. Res. Inf. 2003, 31, 119-133. [CrossRef]

7. Huovila, P.; Koskela, L. Contribution of the principles of lean construction to meet the challenges of sustainable development. In Proceedings of the 6th Annual Conference of the International Group for Lean Construction, Guarujá, Brazil, 13-15 August 1998; pp. 13-15.

8. De Carvalho, A.C.V.; Granja, A.D.; da Silva, V.G. A systematic literature review on integrative lean and sustainability synergies over a building's lifecycle. Sustainability 2017, 9, 1156. [CrossRef]

9. Martínez León, H.C.; Calvo-Amodio, J. Towards lean for sustainability: Understanding the interrelationships between lean and sustainability from a systems thinking perspective. J. Clean. Prod. 2017, 142, 4384-4402. [CrossRef]

10. Florida, R. Lean and Green: The Move to Environmentally Conscious Manufacturing. Calif. Manag. Rev. 1996, 39, 80-105. [CrossRef]

11. Johnson, B.T.; Gunderson, D.E. Educating students concerning recent trends in AEC: A survey of ASC member programs. In Proceedings of the International Proceedings of the 46th Annual Conference, Associated Schools of Construction, Boston, MA, USA, 1 April 2009.

12. Pellicer, E.; Yepes, V.; Ortega, A.J. Method for Planning Graduate Programs in Construction Management. J. Prof. Issues Eng. Educ. Pract. 2013, 139, 33-41. [CrossRef]

13. Jeong, W.S.; Chang, S.; Son, J.W.; Yi, J.S. BIM-integrated construction operation simulation for just-in-time production management. Sustainability 2016, 8, 1106. [CrossRef]

14. Alves, T.C.L.; Azambuja, M.M.; Arnous, B. Teaching Lean Construction: A Survey of Lean Skills and Qualifications Expected By Contractors and Specialty Contractors in 2016. In Proceedings of the 24th International Group for Lean Construction, Boston, MA, USA, 18-24 July 2016; pp. 13-21.

15. Ahmed, S.M.; Yaris, C.; Farooqui, R.U.; Saqib, M. Key Attributes and Skills for Curriculum Improvement for Undergraduate Construction Management Programs. Int. J. Constr. Educ. Res. 2014, 10, 240-254. [CrossRef]

16. Burch, R.F.; Smith, B. Using simulation to teach lean methodologies and the benefits for Millennials. Total Qual. Manag. Bus. Excell. 2017, 30, 320-334. [CrossRef]

17. Becerik-Gerber, B.; Ku, K.; Jazizadeh, F. BIM-Enabled Virtual and Collaborative Construction Engineering and Management. J. Prof. Issues Eng. Educ. Pract. 2012, 138, 234-245. [CrossRef]

18. Clevenger, C.; Glick, S.; del Puerto, C.L. Interoperable Learning Leveraging Building Information Modeling (BIM) in Construction Education. Int. J. Constr. Educ. Res. 2012, 8, 101-118. [CrossRef]

19. Pellicer, E.; Ponz-Tienda, J.L. Teaching and learning lean construction in Spain: A pioneer experience. In Proceedings of the 22th International Group for Lean Construction, Oslo, Norway, 25-27 June 2014; Volume 3, pp. 1245-1256.

20. Nofera, W.; Abdelhamid, T.S.; Lahouti, A. Teaching Lean Construction for University Student(s). In Proceedings of the 23rd International Group for Lean Construction, Perth, Australia, 29-31 July 2015; pp. 424-433.

21. Kuriger, G.W.; Wan, H.; Mirehei, S.M.; Tamma, S.; Chen, F.F. A Web-Based Lean Simulation Game for Office Operations: Training the Other Side of a Lean Enterprise. Simul. Gaming 2009, 41, 487-510. [CrossRef]

22. Pivec, M. Play and learn: Potentials of game-based learning. Br. J. Educ. Technol. 2007, 38, 387-393. [CrossRef]

23. De Freitas, S.; Oliver, M. How can exploratory learning with games and simulations within the curriculum be most effectively evaluated? Comput. Educ. 2006, 46, 249-264. [CrossRef]

24. Dondlinger, M.J. Educational video game design: A review of the literature. J. Appl. Educ. Technol. 2007, 4, 21-31.

25. Torres, M.; Macedo, J. Learning sustainable development with a new simulation game. Simul. Gaming 2000, 31, 119-126. [CrossRef]

26. Qian, M.; Clark, K.R. Game-based Learning and 21st century skills: A review of recent research. Comput. Hum. Behav. 2016, 63, 50-58. [CrossRef]

27. Plass, J.L.; Homer, B.D.; Kinzer, C.K. Foundations of Game-Based Learning. Educ. Psychol. 2015, 50, $258-283$. [CrossRef] 
28. Plass, J.L.; Perlin, K.; Nordlinger, K. The games for learning institute: Research on design patterns for effective educational games. In Proceedings of the Game Developers Conference, San Francisco, CA, USA, 16-20 March 2010.

29. Badurdeen, F.; Marksberry, P.; Hall, A.; Gregory, B. Teaching lean manufacturing with simulations and games: A survey and future directions. Simul. Gaming 2010, 41, 465-486. [CrossRef]

30. Warcup, R.; Reeve, E. Using the Villego(r) simulation to teach the last planner (r) system. Lean Constr. J. 2014, 2014, 1-15.

31. Chua, D.K.H.; Nguyen, Q.T.; Yeoh, K.-W. Plan-It-A Game Approach To Teaching Last Planner Methodology and Lean Construction. In Proceedings of the 4th International Conference on Engineering, Project, and Production Management (EPPM 2013), Bangkok, Thailand, 23-25 October 2013; pp. 33-47.

32. Deif, A. Insights on lean gamification for higher education. Int. J. Lean Six Sigma 2017, 8, 359-376. [CrossRef]

33. Hirota, E.H.; Formoso, C.T. Some directions for developing construction management training programmes on lean construction. In Proceedings of the 6th Annual Conference of the International Group for Lean Construction, Sao Paulo, Brazil, 13-15 August 1998.

34. Brioso, X. Teaching Lean Construction: Pontifical Catholic University of Peru Training Course in Lean Project \& Construction Management. Procedia Eng. 2015, 123, 85-93.

35. Dave, B.; Koskela, L.; Kiviniemi, A.; Owen, R.; Tzortzopoulos, P. Implementing Lean in Construction; CIRIA: London, UK, 2013; ISBN 9780860177272.

36. Womack, J.; Jones, D.; Roos, D. Massachusetts Institute of Technology The Machine That Changed the World: The Story of Lean Production; Harper Collins: New York, NY, USA, 1991.

37. Koskela, L. Making-do: The eighth category of waste. In Proceedings of the 12th Annual Conference of the International Group for Lean Construction, Elsinore, Denmark, 3-5 August 2004; pp. 1-15.

38. Publication Office of the European Union. ECTS Users' Guide; Publications Office of the European Union: Luxembourg, 2015; ISBN 978-92-79-43559-1.

39. Pellicer, E.; Cerveró, F.; Lozano, A.; Ponz-Tienda, J.L. The Last Planner System of Construction Planning and control as a Teaching and Learning Tool. In Proceedings of the 9th International Technology, Education and Development Conference (INTED 2015), Madrid, Spain, 2-4 March 2015; pp. 4877-4884.

40. Saldaña, J. Longitudinal Qualitative Research: Analyzing Change through; Altamira Press: New York, NY, USA, 2003.

41. Hermanowicz, J.C. Longitudinal Qualitative Research. In Handbook of the Life Course; Springer: Berlin/Heidelberg, Germany, 2016.

42. Tomsom, R.; MCLeod, J. New frontiers in qualitative longitudinal research: An agenda for research. Int. J. Soc. Res. Methodol. 2015, 18, 243-250.

43. Bavelas, A. The five squares problem: An instruction aid in group cooperation. Stud. Pers. Psychol. 1973, 5, 29-38.

44. Bosse, T.; Hoogendoorn, M.; Jonker, C.M. The Distributed Weighing Problem: A Lesson in Cooperation Without Communication. In MATES 2005: Multiagent System Technologies; Eymann, T., Klügl, F., Lamersdorf, W., Klusch, M., Huhns, M.N., Eds.; Springer: Berlin/Heidelberg, Germany, 2005; pp. 191-203.

45. Martin, R.R.; Weber, P.L.; Henderson, W.E.; Lafontaine, K.R.; Sachs, R.E.; Roth, J.; Cox, K.J.; Schaffner, D. Broken Squares; Building Dynamic Groups: Columbus, OH, USA, 2000; pp. 1-5.

46. Lean Construction Institute. Make a Card Simulation. Available online: https://www.leanconstruction.org/ learning/game-simulations/make-a-card-simulation/ (accessed on 24 September 2019).

47. Thomas, H.R. Labor productivity and work sampling: The bottom line. J. Constr. Eng. Manag. 1992, 117, 423-444. [CrossRef]

48. Gouett, M.C.; Haas, C.T.; Goodrum, P.M.; Caldas, C.H. Activity Analysis for Direct-Work Rate Improvement in Construction. J. Constr. Eng. Manag. 2011, 137, 1117-1124. [CrossRef]

49. Field, A. Discovering Statistics Using IBM SPSS Statistics; SAGE Publications: Los Angeles, CA, USA, 2013; ISBN 9781847879066.

50. Dao, B.; Kermanshachi, S.; Shane, J.; Anderson, S.; Hare, E. Exploring and assessing project complexity. J. Constr. Eng. 2geiManag. 2017, 143, 04016126. [CrossRef]

51. Delago, L.C.; Machado, M.E.F.H.S.; de Brito, F.O.; Landgraf, G.C.; de Andrade Schroeder, M.; Torezzan, C. Learning Lean Philosophy through 3D Game-Based Simulation. In Proceedings of the 2016 Winter Simulation Conference (WSC), Washington, DC, USA, 11-14 December 2016; ISBN 9781509044849. 
52. Park, C.S.; Le, Q.T.; Pedro, A.; Lim, C.R. Interactive Building Anatomy Modeling for Experiential Building Construction Education. J. Prof. Issues Eng. Educ. Pract. 2016, 142, 04015019. [CrossRef]

53. Da Rocha, C.G.; Miron, L.I.G. The House Factory: A Simulation Game for Understanding Mass Customization in House Building. J. Prof. Issues Eng. Educ. Pract. 2017, 144, 5017007. [CrossRef]

54. Shaaruddin, J.; Mohamad, M. Identifying the Effectiveness of Active Learning Strategies and Benefits in Curriculum and Pedagogy Course for Undergraduate TESL Students. Creat. Educ. 2017, 8, 2312-2324. [CrossRef]

(C) 2019 by the authors. Licensee MDPI, Basel, Switzerland. This article is an open access article distributed under the terms and conditions of the Creative Commons Attribution (CC BY) license (http://creativecommons.org/licenses/by/4.0/). 